\title{
Analysis of $N$-glycans in embryonated chicken egg chorioallantoic and amniotic cells responsible for binding and adaptation of human and avian influenza viruses
}

\author{
Nongluk Sriwilaijaroen • Sachiko Kondo • \\ Hirokazu Yagi • Prapon Wilairat • Hiroaki Hiramatsu • \\ Morihiro Ito • Yasuhiko Ito • Koichi Kato • \\ Yasuo Suzuki
}

Received: 7 June 2008 /Revised: 23 August 2008 / Accepted: 15 September 2008 /Published online: 14 October 2008

(C) The Author(s) 2008. This article is published with open access at Springerlink.com

\begin{abstract}
The initial step essential in influenza virus infection is specific binding of viral hemagglutinin to host cell-surface glycan receptors. Influenza A virus specificity for the host is mediated by viral envelope hemagglutinin, that binds to receptors containing glycans with terminal sialic acids. Human viruses preferentially bind to $\alpha 2 \rightarrow 6$ linked sialic acids on receptors of host cells, whereas avian viruses are specific for the $\alpha 2 \rightarrow 3$ linkage on the target
\end{abstract}

N. Sriwilaijaroen $\cdot$ H. Hiramatsu $\cdot$ M. Ito $\cdot$ Y. Ito $\cdot$ Y. Suzuki

Department of Biomedical Sciences,

College of Life and Health Sciences,

Chubu University, 1200 Matsumoto-cho,

Kasugai, Aichi 487-8501, Japan

N. Sriwilaijaroen

Faculty of Medicine, Thammasat University,

Rangsit Campus, Pathumthani 12120, Thailand

S. Kondo $\cdot \mathrm{H}$. Yagi $\cdot$ K. Kato

Graduate School of Pharmaceutical Sciences,

Nagoya City University,

3-1 Tanabe-dori, Mizuho-ku,

Nagoya 467-8603, Japan

$\mathrm{S}$. Kondo $\cdot \mathrm{K}$. Kato

GLYENCE Co., Ltd., 2-22-8 Chikusa, Chikusa-ku,

Nagoya 464-0858, Japan

H. Yagi $\cdot$ K. Kato $\cdot$ Y. Suzuki

CREST, Japan Science and Technology Agency,

4-1-8 Honcho, Kawaguchi, Japan

P. Wilairat

Department of Biochemistry, Faculty of Science,

Mahidol University, Bangkok, Thailand cells. Human influenza virus isolates more efficiently infect amniotic membrane (AM) cells than chorioallantoic membrane (CAM) cells. $N$-glycans were isolated from AM and CAM cells of 10-day-old chicken embryonated eggs and their structures were analyzed by multi-dimensional HPLC mapping and MALDI-TOF-MS techniques. Terminal $\mathrm{N}$ acetylneuraminic acid contents in the two cell types were similar. However, molar percents of $\alpha 2 \rightarrow 3$ linkage prefer-

K. Kato

The Glycoscience Institute,

Ochanomizu University,

2-1-1 Ohtsuka, Bunkyo-ku,

Tokyo 112-8610, Japan

K. Kato

Institute for Molecular Science

National Institutes of Natural Sciences,

5-1 Higashiyama Myodaiji,

Okazaki 444-8787, Japan

Y. Suzuki

Global COE Program for Innovation

in Human Health Sciences, University of Shizuoka

School of Pharmaceutical Sciences,

52-1 Yada, Shizuoka 422-8526, Japan

Present address:

Y. Suzuki $(\bowtie)$

Department of Biomedical Sciences,

College of Life and Health Sciences,

Chubu University, 1200 Matsumoto-cho,

Kasugai, Aichi 487-8501, Japan

e-mail: suzukiy@isc.chubu.ac.jp 
entially bound by avian influenza virus were 27.2 in CAM cells and 15.4 in AM cells, whereas those of $\alpha 2 \rightarrow 6$ linkage favored by human influenza virus were 8.3 (CAM) and 14.2 (AM). Molar percents of sulfated glycans, recognized by human influenza virus, in CAM and AM cells were 3.8 and 12.7, respectively. These results have revealed structures and molar percents of $\mathrm{N}$-glycans in CAM and AM cells important in determining human and avian influenza virus infection and viral adaptation.

Keywords Influenza virus $\cdot N$-glycans . HPLC-MALDI-TOF mapping - Chorioallantoic membrane . Amniotic membrane $\cdot$ Host cell receptor specificity

\begin{tabular}{|c|c|}
\hline \multicolumn{2}{|c|}{ Abbreviations } \\
\hline AM & amniotic membrane \\
\hline CAM & chorioallantoic membrane \\
\hline DEAE & diethylamino ethanol \\
\hline Gal & galactose \\
\hline GalNAc & $N$-acetylgalactosamine \\
\hline GlcNAc & $N$-acetylglucosamine \\
\hline GU & glucose unit \\
\hline HA & hemagglutinin \\
\hline LacNAc & $N$-acetyllactosamine \\
\hline MALDI- & matrix-assisted laser desorption \\
\hline TOF-MS & ionization time-of-flight mass spectrometry \\
\hline MDCK & Madin Darby canine kidney \\
\hline Neu5Ac & 5-N-acetylneuraminic acid \\
\hline Neu5Gc & 5 - $N$-glycolylneuraminic acid \\
\hline ODS & octadecyl silica \\
\hline PA & pyridylamino \\
\hline SiaLac & sialyl- $N$-acetyllactosamine \\
\hline
\end{tabular}

\section{Introduction}

Influenza is caused by enveloped single-stranded negativesense RNA viruses, including A, B and C types that differ in their nucleoproteins and matrix proteins. Influenza B and $\mathrm{C}$ viruses can cause epidemic influenza mainly in humans, whereas influenza A viruses have caused epidemics and sometimes pandemics of influenza in both humans and animals $[1,2]$. Influenza viruses are enveloped by glycoproteins with antigenic hemagglutinins (HAs; H1-H16 subtypes), which have an important role in binding to oligosaccharide (glycan) receptors on glycoproteins or glycolipids of host cell surfaces, triggering endocytosis of the virus into host cells $[1,3]$. Results of a recent in vivo study have shown that $\mathrm{N}$-glycans are required for influenza virus infection and entry into host cells of influenza viruses, at least influenza $\mathrm{A}(\mathrm{H} 1 \mathrm{~N} 1$ and $\mathrm{H} 3 \mathrm{~N} 2)$ and influenza $\mathrm{B}$ viruses [4]. Antigenic HA of human and avian influenza A isolates recognizes sialic acid with $\alpha 2 \rightarrow 6$ and $\alpha 2 \rightarrow 3$ linkages respectively, and HA of type B viruses prefers the $\alpha 2-6$-linked sialic acid [2, 5-7]. HA of influenza $\mathrm{C}$ viruses requires sialic acid with a 9-O-acetyl group for attachment $[8,9]$. Importantly, HAs have been known to be sugar (glycan)-recognizing proteins that determine transmission and virulence of influenza viruses $[1,2,10]$.

Due to the difficulty of obtaining sufficient amounts of influenza viruses isolated from humans and avians for studies such as studies on viral biology, vaccine production and exploration of new antiviral drugs, cultivation of viruses is needed. Viruses isolated from avian and human hosts have traditionally been grown in chorioallantoic and amniotic cavities, respectively, of chicken embryonated eggs. This is because isolated human influenza viruses replicate less efficiently if they are not adapted, whereas isolated avian influenza viruses replicate more efficiently in a chorioallantoic cavity [11-13]. What is responsible for the replication requirement of these isolated viruses in their respective cavity is not known.

Mammalian Madin Darby canine kidney (MDCK) cells have become routinely used for cultivation of isolated human influenza viruses, because the newly formed viruses are antigenically similar to the original isolates [14-16]. Human influenza viruses grown in embryonated chicken eggs select variants with amino acid mutations in the receptor-binding site of the HA molecule (host adaptation) in order to enable the viruses to grow well in these particular host cells [13, 17-19].

Several studies have shown that different cell types contain different amounts, types and linkages of sugar chains by using sialyl linkage-specific lectins [20-24]. Chorioallantoic membrane (CAM) cells were found to contain $\operatorname{Neu} 5 \operatorname{Ac}(\alpha 2 \rightarrow 3)$ Gal (5- $N$-acetylneuraminic acid (Neu5Ac) linked to galactose (Gal) by $\alpha 2-3$ linkage), and amniotic membrane (AM) and MDCK cells contain both Neu5Ac $\alpha 2 \rightarrow$ Gal and Neu5Ac $\alpha 2 \rightarrow$ Gal [25]. However, there has been no report in which the quantity and structure of $N$-glycans present on these two types of cells are described.

By using a multi-dimensional high-performance liquid chromatography (HPLC) mapping technique [26-28], we have been able to carry out $\mathrm{N}$-glycosylation profiling in a quantitative manner at molecular, cellular, and organ levels. This prompts us to characterize the $N$-glycans expressed on CAM and AM cells of 10-day-old chicken embryonated eggs.

\section{Materials and methods}

Preparation of $\mathrm{N}$-glycans from CAM and AM cells

CAM and AM cells of 10-day-old chicken embryonated eggs were removed carefully using fine forceps from the 
inner shell membrane and the embryo, respectively, washed thoroughly with cold PBS to remove blood cells, and lyophilized. Dried CAM (22.5 mg) and AM (20.3 mg) was taken and their lipid was sequentially extracted from the cells with $80 \%$ ethanol, $100 \%$ ethanol, chloroform/methanol $(2: 1, v / v)$, chloroform/methanol/ $\mathrm{H}_{2} \mathrm{O}(1: 2: 0.8, v / v / v)$, and $80 \%$ acetone. The cell residues were proteolyzed with pepsin and further digested with glycoamidase A to release $\mathrm{N}$-glycans. The resultant peptidic materials were hydrolyzed by treatment with pronase [28, 29]. The glycan fraction was then purified by a Bio-Gel P-2 column $(1 \mathrm{~cm}$ i.d. $\times 30 \mathrm{~cm})$ and evaporated to dryness.

Fluorescent derivatization of $N$-glycans

with 2-aminopyridine and HPLC mapping

The reducing ends of $\mathrm{N}$-glycans were labeled with a fluorescent reagent, 2-aminopyridine [30]. The pyridylamino-labeled glycan (PA-glycan) mixture was then purified by gel filtration on a Sephadex G-15 column $(1 \mathrm{~cm}$ i.d. $\times$ $30 \mathrm{~cm}$ ) to remove excess reagents. The purified PA-glycan mixture was firstly subjected to an anion exchange chromatography [TSKgel diethylamino ethanol (DEAE)5PW column; $7.5 \mathrm{~mm}$ i.d. $\times 75 \mathrm{~mm}$; Tosoh, Tokyo, Japan]. Each peak fraction from the DEAE column was collected, evaporated, and analyzed by reverse-phase HPLC using a Shim-pack HRC-octadecyl silica (ODS) column $(6.0 \mathrm{~mm}$ i.d. $\times 150 \mathrm{~mm}$, Shimadzu, Kyoto, Japan). Individual peak fractions from the ODS column were then isolated using a size fractionation column, TSK-gel amide-80 (Tosoh, Tokyo, Japan) as conditions reported previously [28, 29]. The elution times of the individual peaks from the amidesilica and ODS columns were normalized with respect to PA-derivatized isomalto-oligosaccharides of polymerization degree and represented in units of glucose (GU). The identification of $\mathrm{N}$-glycan structures was based on their elution positions on three kinds of HPLC columns in comparison with PA-glycans in the GALAXY database (http://www.glycoanalysis.info/galaxy2/ENG/systemin1. jsp) [27].

Exo-glycosidase digestion and matrix-assisted laser desorption ionization time-of-flight mass spectrometric (MALDI-TOF-MS) analysis

PA-glycans, which did not agree with any of the $N$-glycans so far registered in GALAXY, were trimmed by exoglycosidase $(\alpha$-sialidase, $\alpha 2,3$-sialidase, $\alpha$-fucosidase, $\beta$ galactosidase and $\beta$ - $N$-acetylglucosaminidase) treatment according to previously described [29] to become identical to known ones. Then the reaction products were subjected to MALDI-TOF-MS spectrometric analysis and operated as described previously [31].

\section{Results and discussion}

$\mathrm{N}$-glycans released from CAM and AM cells by glycoamidase A and labeled with PA were separated by a DEAE column. Four peaks were eluted at 2, 10-15.5, 21-25.5 and 27-28.5 min (Fig. 1a). These peak fractions were identified as a neutral glycan (peak 1) and three kinds of acidic glycans, namely, monosialyated (peak 2), disialyated (peak 3 ) and disulfated (peak 4) glycan. Each DEAE peak fraction was further analyzed by ODS column. As shown in Fig. 1b-e, 13 major peaks (N1-N12'), 11 major peaks (M1-11), 5 major peaks (D1-D5) and 1 major peak (D6) were separated from DEAE peaks 1, 2, 3 and 4, respectively.

Based on the peak areas in the chromatograms shown in Fig. 1b-e, molar percents of peaks 1, 2, 3 and 4 from CAM cells were 59.7, 29.5, 9.3 and 1.5 , respectively, and those from AM cells were 56.7, 29.4, 9.5 and 4.4, respectively. The ratio of molar percent of neutral to acidic glycans was 1.5:1.0 for both CAM and AM cells (Fig. 2). However, the total amount of $N$-glycans derived from CAM cells (114.6 $\mathrm{pmol} \mathrm{mg}^{-1}$ dry cells) was 2.4-times than that derived from AM cells (47.0 $\mathrm{pmol} \mathrm{mg}^{-1}$ dry cells).

The PA-oligosaccharide was identified on the basis of coincidence of elution time normalized in GU with those on the HPLC map. For example, the major sialo- $N$-glycan corresponding to peak M7 was eluted at $14.8 \mathrm{GU}$ on the ODS column and at $6.8 \mathrm{GU}$ on the amide column. The elution data set was in good agreement with a known reference $\alpha 2 \rightarrow 3$ sialyl glycan, Gal $\beta 1 \rightarrow 4 \mathrm{GlcNAc} \beta 1 \rightarrow$ $2 \mathrm{Man} \alpha 1 \rightarrow 6$ (Neu $5 \mathrm{Ac} \alpha 2 \rightarrow 3 \mathrm{Gal} \beta 1 \rightarrow 4 \mathrm{GlcNAc} \beta 1 \rightarrow 2$ Man $\alpha 1 \rightarrow 3$ )Man $\beta 1 \rightarrow 4$ GlcNAc $\beta 1 \rightarrow 4$ (Fuc $\alpha 1 \rightarrow 6$ ) GlcNAcPA (code no. 1A3-210.4 in the GALAXY database). By co-chromatography and the MALDI-TOF-MS analyses, we confirmed the structure of this PA-oligosaccharide.

The sialylated PA-glycans corresponding to the fractions M9, M10, M11 and D4 did not agree with any of the PAglycans so far registered in the GALAXY. These PAglycans were trimmed by exoglycosidase treatments to become identical to known ones. Taking into account the specificities of the exoglycosidases used, the original structures of these PA-glycans were uniquely determined.

In a similar way, we identified the remaining 27 kinds of the $N$-glycans derived from CAM and AM cells, which consist of neutral and sialyl oligosaccharides, along with sulfated glycans.

The molar percents of neutral $N$-glycans detected, divided into high-mannose-type, galactose-terminal, $\mathrm{N}$ acetylglucosamine (GlcNAc)-terminal and others, were 18.6, 29.1, 8.2 and 3.8, respectively, in CAM cells, and 30.1, 21.5, 0.0 and 5.1, respectively, in AM cells (Table 1 and Fig. 2). A previous study has shown that human influenza viruses can react with mannose-binding lectins of 
(a)

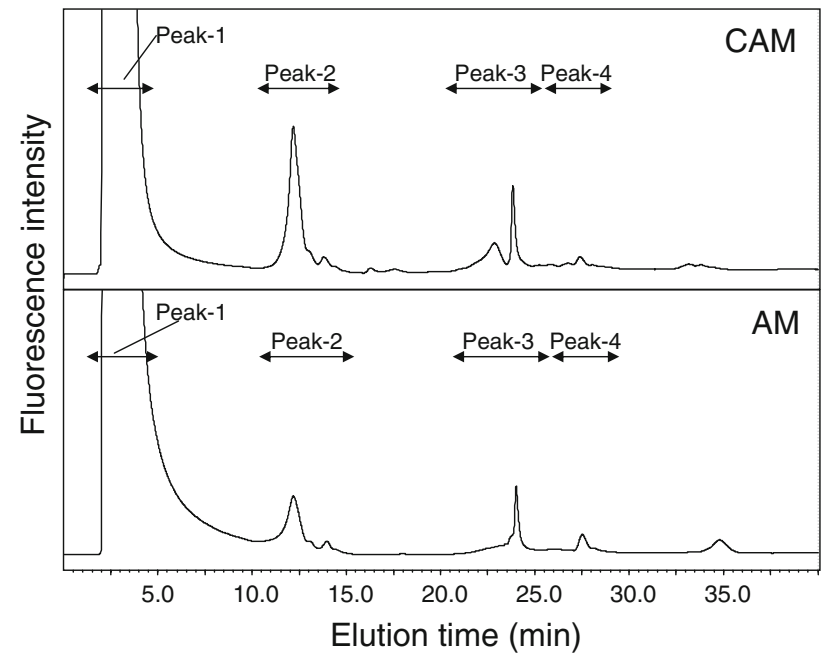

(c)

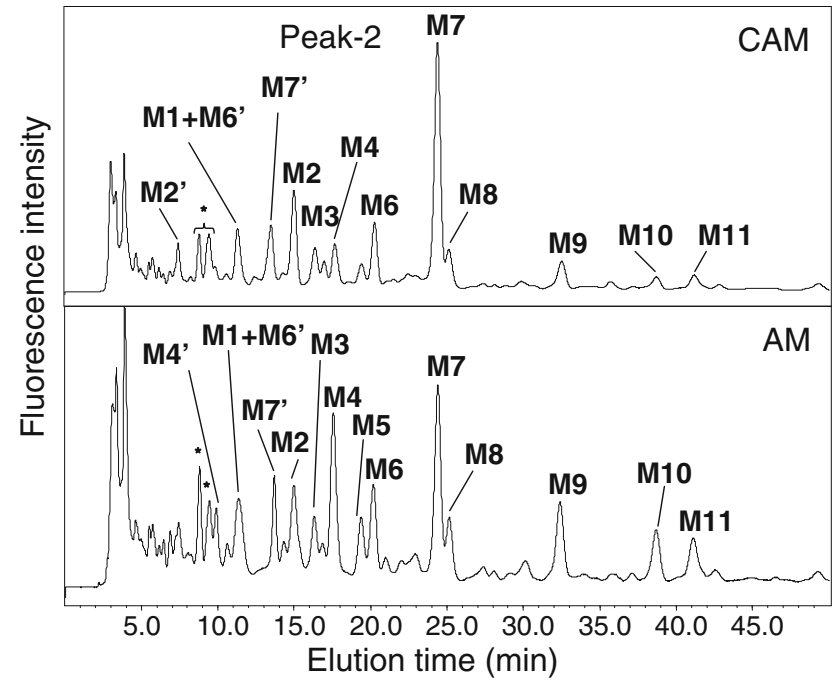

(e)

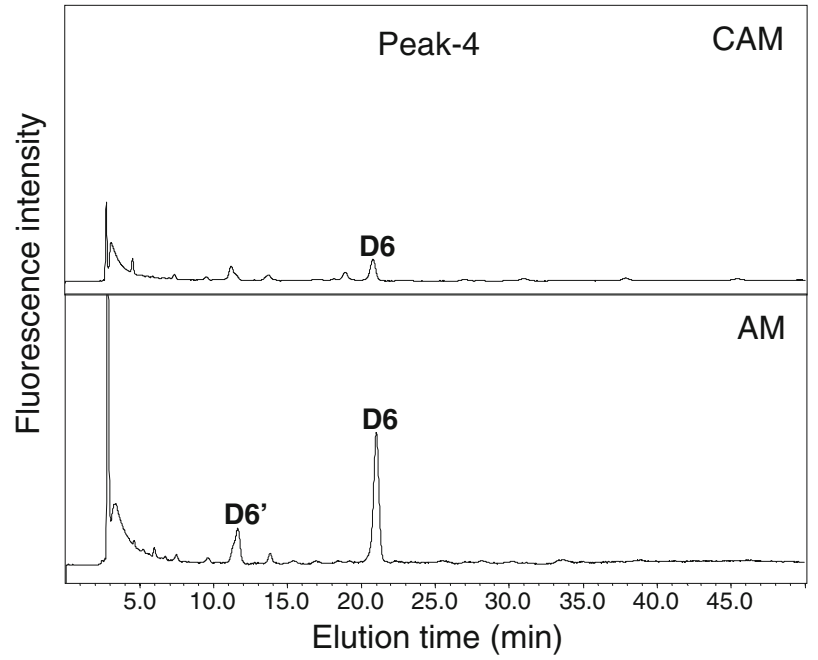

(b)

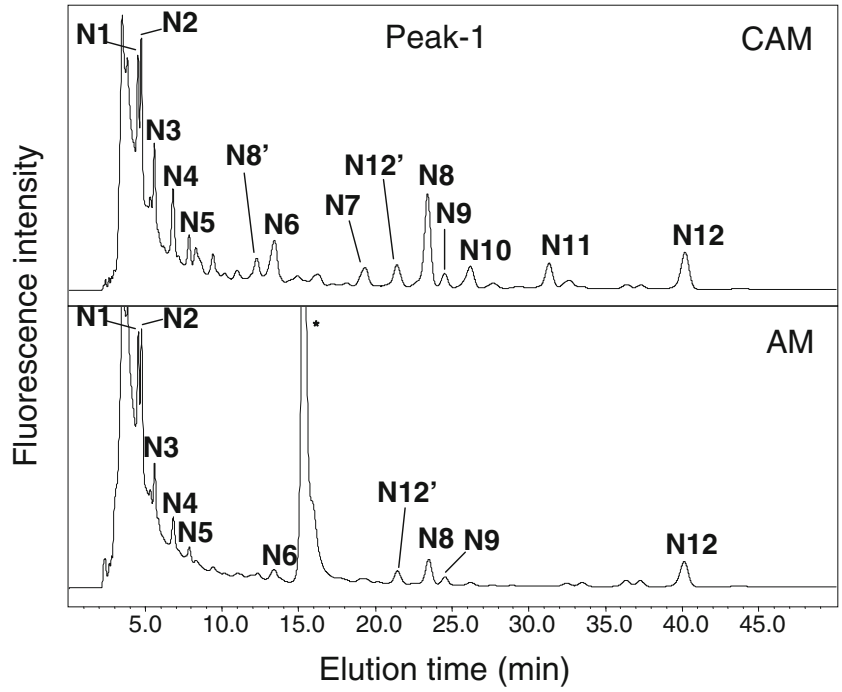

(d)

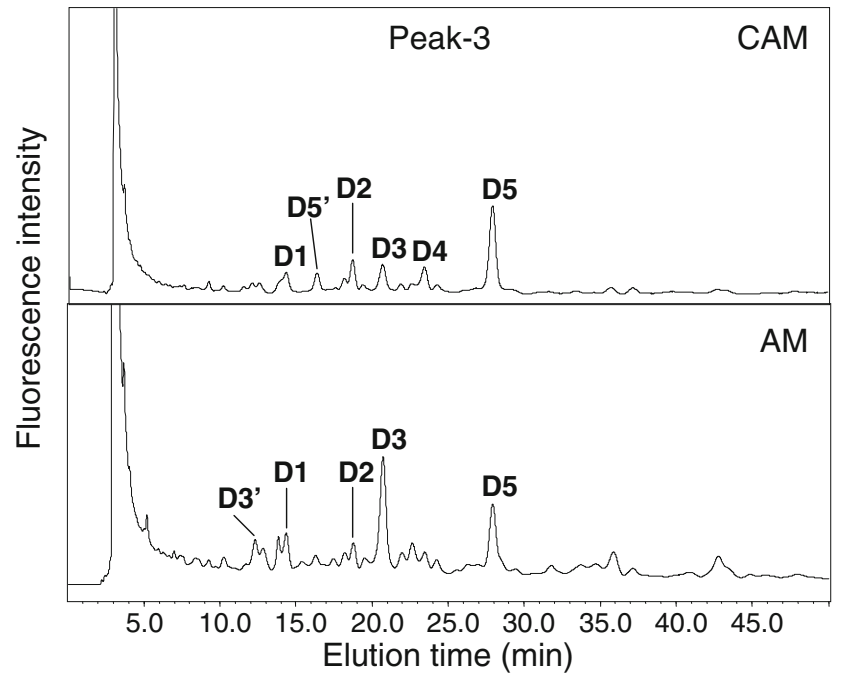


Fig. 1 Comparison of HPLC profiles (a-e) of pyridylamino (PA) derivatives of $N$-linked glycans isolated from chorioallantoic membrane (CAM) and amniotic membrane (AM) cells. The derivatized $\mathrm{N}$-glycans from CAM and AM cells were separated on an ion exchange diethylamino ethanol (DEAE) column (a). Peaks 1, 2, 3 and 4 indicate the elution positions of the derivatized $N$-glycans with the corresponding negative charged, neutral, monosialylated, disialylated and disulfated glycans, respectively. Fractions of peaks $1,2,3$ and 4 were further separated on a reversed-phase octadecyl silica (ODS) column as described in the text, giving elution profiles of $\mathbf{b}-\mathbf{e}$, respectively. Peaks in profiles $\mathbf{b}-\mathbf{e}$ are expressed as N1-13 (neutral), M1-11 (monosialylated) and D1-6 (disialylated or disulfated); their corresponding structures are shown in Table 1. The epimeric by-products of the pyridylamination reaction are indicated with a prime, e.g. $\mathrm{M} 2^{\prime}$. Asterisks indicate the fractions containing no detectable PA-oligosaccharides

the collectin family and infect murine macrophages expressing the mannose receptor and that the infection was inhibited by yeast mannan [32].

Negatively charged glycans, including sialylated and sulfated glycans, are the major viral receptors [6]. Influenza viruses preferentially bind to glycans terminated by sialic acid, mostly Neu5Ac derivative, either $\operatorname{Neu} 5 \mathrm{Ac}(\alpha 2 \rightarrow 3) \mathrm{Gal}$ or Neu5Ac $(\alpha 2 \rightarrow 6) \mathrm{Gal}$; human isolates predominantly bind to $\operatorname{Neu} 5 \mathrm{Ac}(\alpha 2 \rightarrow 6) \mathrm{Gal}$, while avian isolates mainly bind to $\operatorname{Neu} 5 \operatorname{Ac}(\alpha 2 \rightarrow 3)$ Gal [7, 10, 33-40]. Glycan microarray analyses detected differences in human and avian influenza virus HA specificity, such as preferences for fucosylation and sialylation at positions 2 (Gal) and 3 (GlcNAc, GalNAc) of the terminal trisaccharide [41], and also showed that highly pathogenic avian influenza H5N1 viruses bind preferentially to $\operatorname{Sia}(\alpha 2 \rightarrow 3) \mathrm{Gal}$ structure [42] and highly pathogenic avian H7N7 viruses from The Netherlands in 2003 maintain the classic avian-binding preference for $\alpha 2 \rightarrow 3$ linked sialic acids [43]. Recently, it was reported that a characteristic structural topology enables specific binding of HA to $\alpha 2 \rightarrow 6$ sialylated glycans and human adapted $\mathrm{H} 1 \mathrm{~N} 1$ and $\mathrm{H} 3 \mathrm{~N} 2$ viruses specifically bind to long sialylated glycans containing tandem lactosamine structure such as $\mathrm{Sia}(\alpha 2 \rightarrow 6) \mathrm{Gal}(\beta 1 \rightarrow 4) \mathrm{GlcNAc}$ $(\beta 1 \rightarrow 3) \mathrm{Gal}(\beta 1 \rightarrow 4) \operatorname{GlcNAc}(\beta 1 \rightarrow 3) \mathrm{Gal}$-structures [10]. In $\mathrm{CAM}$ and $\mathrm{AM}$, terminal short sialylated trisaccharide structure of $N$-glycans, Neu5Ac $(\alpha 2 \rightarrow 3) \operatorname{Gal}(\beta 1 \rightarrow 4)$ GlcNAc-and Neu5Ac $(\alpha 2,6)$ Gal $(\beta 1,4)$ GlcNAc-, were detected, but long tandem $N$-acetyllactosamine structure was not found. Some neutral and sialyl-sugar chains of $N$ glycans in CAM and AM were fucosylated. The molar percents of terminal Neu5Ac $(\alpha 2 \rightarrow 3)$ Gal and Neu5Ac $(\alpha 2 \rightarrow 6)$ Gal derived from CAM cells were significantly different to those from AM cells: 27.2 and 8.3, respectively, for CAM cells, and 15.4 and 14.2 respectively, for AM cells (Table 1 and Fig. 2). This is in agreement with the results of a previous study using a qualitative lectin assay [25] and explains why CAM cells are susceptible to avian but not human influenza viruses, while AM cells are recognized by human influenza viruses. Moreover, the presence of similar molar percents of Neu5Ac $(\alpha 2 \rightarrow 3) \mathrm{Gal}$ and $\operatorname{Neu} 5 \operatorname{Ac}(\alpha 2 \rightarrow 6)$ Gal in AM cells may explain why human influenza viruses grown in AM cells are easily adapted from human-receptor to avian-receptor specificity with amino acid substitutions that cluster around the receptor-binding site of the HA molecule as described previously [13, 18, 19, 25]. Three subtypes of avian influenza viruses, H9N2, H7N7 and highly pathogenic $\mathrm{H} 5 \mathrm{~N} 1$, have been reported in humans in recent years $[44,45]$. Human lower respiratory tissues and
Fig. 2 Comparison of percent contents of $\mathrm{N}$-glycans of cells derived from chorioallantoic (CAM) and amniotic (AM) membranes. The data plotted correspond to percent glycan content in Table 1

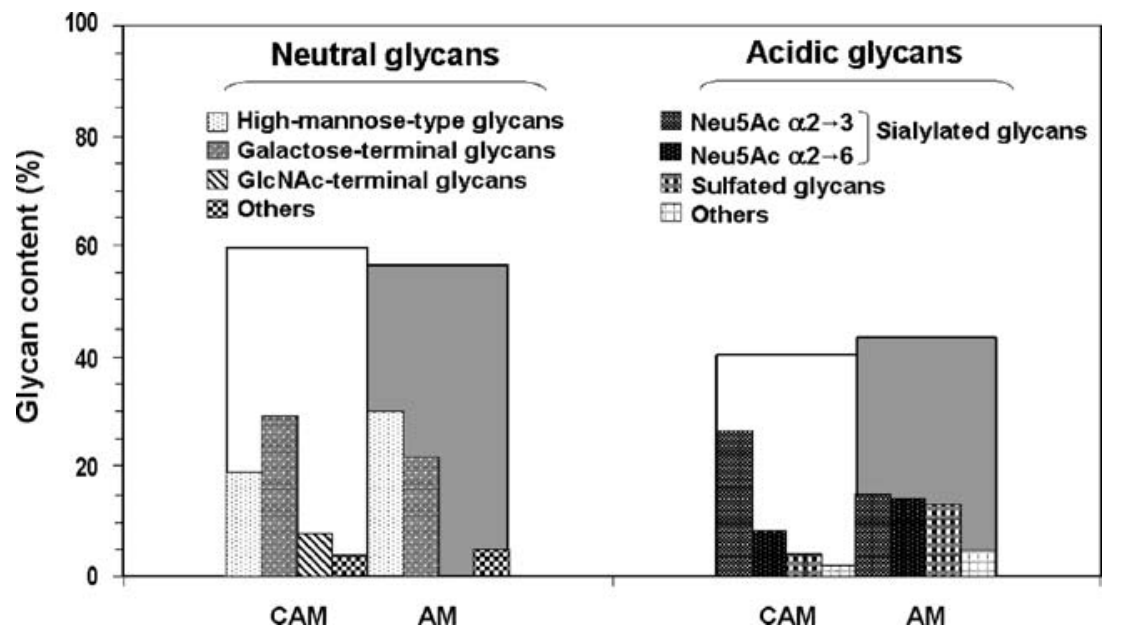


Table 1 Structures and molar percents of $N$-linked glycans of chorioallantoic membrane (CAM) and amniotic membrane (AM) cells isolated from 10-day-old embryonated eggs

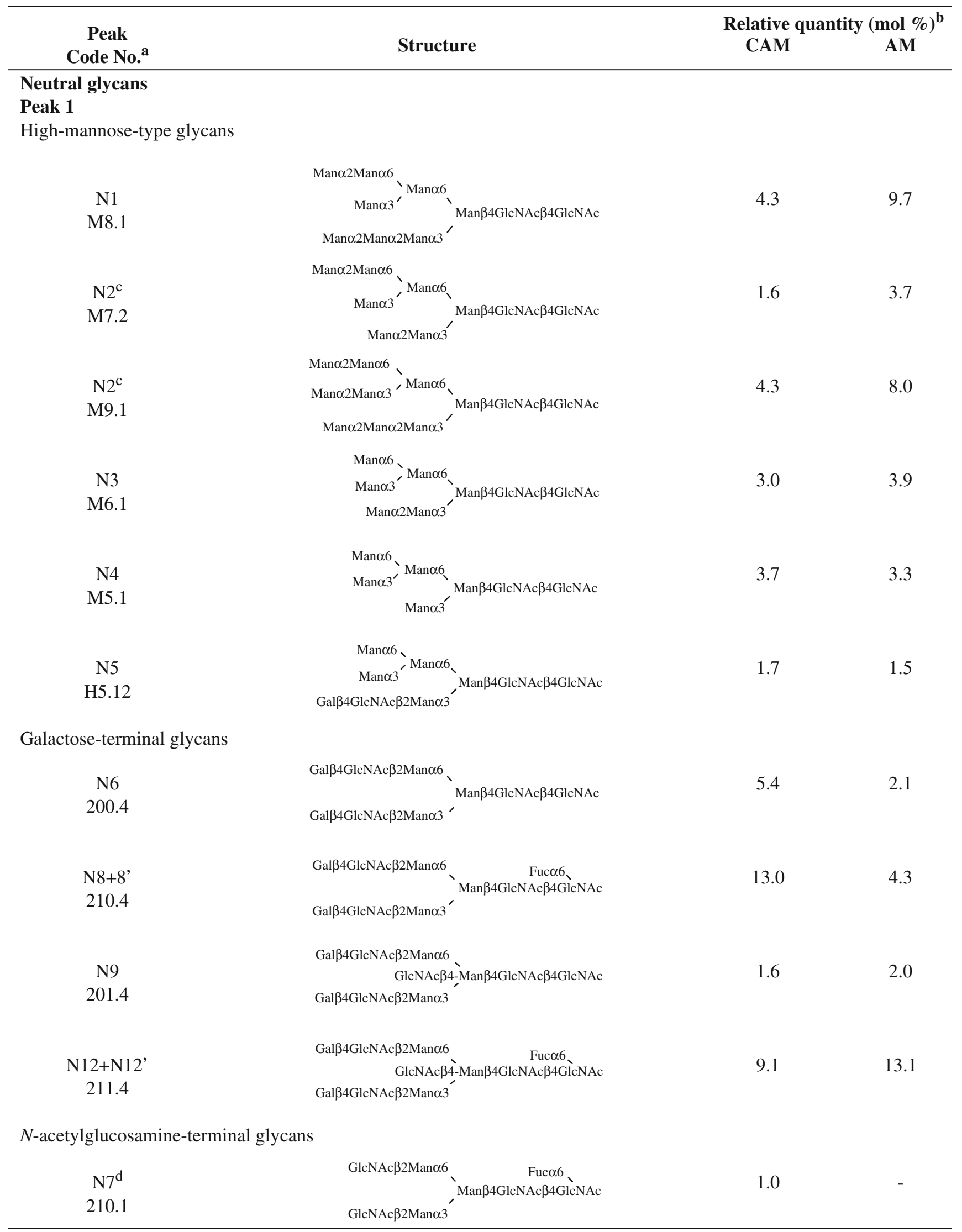


Table 1 (continued)

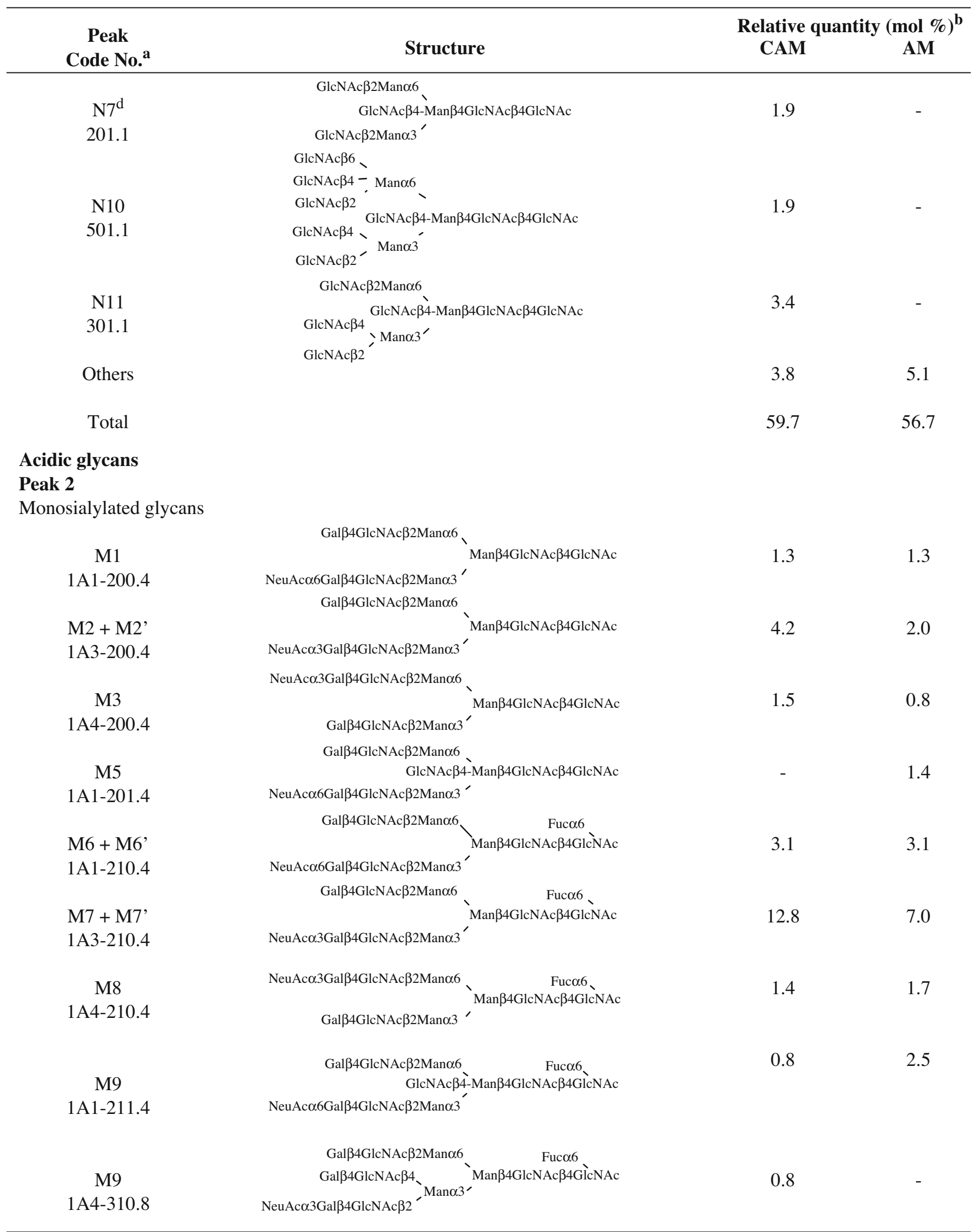


Table 1 (continued)

\begin{tabular}{|c|c|c|c|}
\hline \multirow{2}{*}{$\begin{array}{c}\text { Peak } \\
\text { Code No. }\end{array}$} & \multirow[b]{2}{*}{ Structure } & \multicolumn{2}{|c|}{ Relative quantity $(\mathrm{mol} \%)^{b}$} \\
\hline & & CAM & $\mathbf{A M}$ \\
\hline $\begin{array}{c}\text { M10 } \\
1 \mathrm{~A} 3-211.4\end{array}$ & $\begin{array}{c}\text { Gal } \beta 4 G l c N A c \beta 2 M a n \alpha 6 \\
\text { GlcNAc } \beta 4-M a n \beta 4 G l c N A c \beta 4 G l c N A c \\
\text { NeuAc } \alpha 3 \text { Gal } \beta 4 G l c N A c \beta 2 M a n \alpha 3\end{array}$ & 0.5 & 1.8 \\
\hline $\begin{array}{c}\text { M11 } \\
\text { 1A2-211.4 }\end{array}$ & 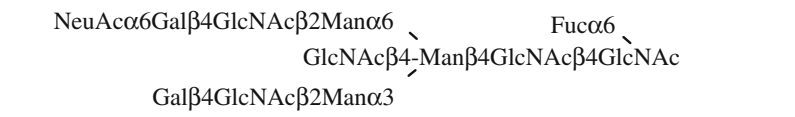 & 0.7 & 1.3 \\
\hline $\begin{array}{l}\text { Monosulfated gly } \\
\text { M4 + M4 }\end{array}$ & $(\mathrm{Hex})_{4}(\mathrm{HexNAc})_{5}(\text { DeoxyHex })_{1}\left(\mathrm{HSO}_{3}\right)_{1}{ }^{\mathrm{e}}$ & 1.6 & 4.8 \\
\hline $\begin{array}{l}\text { Others } \\
\text { Total }\end{array}$ & & $\begin{array}{l}0.8 \\
29.5\end{array}$ & $\begin{array}{r}1.7 \\
29.4\end{array}$ \\
\hline \multicolumn{4}{|c|}{$\begin{array}{l}\text { Peak } 3 \\
\text { Disialyated glycans }\end{array}$} \\
\hline $\begin{array}{c}\text { D1 } \\
\text { 2A1-200.4 }\end{array}$ & 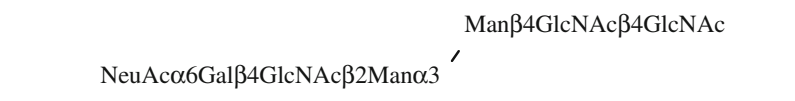 & 0.7 & 0.8 \\
\hline $\begin{array}{c}\text { D2 } \\
\text { 2A4-200.4 }\end{array}$ & $\begin{array}{c}\text { NeuAc } \alpha 3 \text { Gal } \beta 4 G l c N A c \beta 2 M a n \alpha 6 \\
\text { NeuAc } \alpha 3 \text { Gal } \beta 4 G l c N A c \beta 2 M a n \alpha 3 \\
\text { Man } \beta 4 G l c N A c \beta 4 G l c N A c\end{array}$ & 1.0 & 0.5 \\
\hline $\begin{array}{c}\text { D4 } \\
\text { 2A3-210.4 }\end{array}$ & $\begin{array}{l}\text { NeuAc } \alpha 3 \mathrm{Gal} \beta 4 \mathrm{GlcNAc} \beta 2 \mathrm{Man} \alpha 6 \\
{\text { NeuAc } \alpha 6 \mathrm{Gal} \beta 4 \mathrm{GlcNAc} \beta 2 M a n \alpha 3^{\prime}}_{\operatorname{Man} \beta 4 \mathrm{GlcNAc} \beta 4 \mathrm{GlcNAc}}\end{array}$ & 0.8 & - \\
\hline $\begin{array}{l}\mathrm{D} 5+\mathrm{D} 5 \\
2 \mathrm{~A} 4-210.4\end{array}$ & $\begin{array}{l}\text { NeuAc } \alpha 3 \text { Gal } \beta 4 G l c N A c \beta 2 M a n \alpha 6 \\
\text { NeuAc } \alpha 3 \text { Gal } \beta 4 G l c N A c \beta 2 M a n \alpha 3\end{array}$ & 4.6 & 1.6 \\
\hline \multicolumn{4}{|c|}{ Monosialylated and monosulfated glycan } \\
\hline D3 + D3 & $(\operatorname{Hex})_{4}(\operatorname{HexNAc})_{5}(\text { DeoxyHex })_{1}\left(\mathrm{HSO}_{3}\right)_{1}(\mathrm{NeuAc} \alpha 2,6)_{1}{ }^{\mathrm{e}}$ & 1.3 & 3.8 \\
\hline Others & & 0.9 & 2.8 \\
\hline Total & & 9.3 & 9.5 \\
\hline $\begin{array}{l}\text { Peak } 4 \\
\text { Disulfated glycan }\end{array}$ & & & \\
\hline D6 + D6 & $(\mathrm{Hex})_{3}(\mathrm{HexNAc})_{6}(\text { DeoxyHex })_{1}\left(\mathrm{HSO}_{3}\right)_{1}^{\mathrm{e}}$ & 0.9 & 4.1 \\
\hline Others & & 0.6 & 0.3 \\
\hline Total & & 1.5 & 4.4 \\
\hline
\end{tabular}

$\mathrm{Hex}$ hexose, $\mathrm{HexNAc} \mathrm{N}$-acetylhexosamine, DeoxyHex deoxyhexose, $\mathrm{HSO}_{3}$ sulfate group

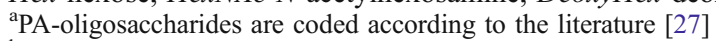

${ }^{b}$ Molar percent of glycan content in CAM and AM cells was calculated on the basis of peak area in Fig. 1b-e by comparison with total glycan content in CAM and AM cells, respectively

${ }^{c}$ Fraction N2 from the ODS column was separated into two subfractions on the amide column. The molar percent of each glycan was calculated on the basis of peak areas in the elution profile on the amide column

${ }^{\mathrm{d}}$ Molar percent of each glycan was calculated on the basis of peak intensity in the MALDI-TOF-MS spectrum

${ }^{\mathrm{e}}$ Carbohydrate composition was estimated on the basis of MALDI-TOF-MS data 
lungs to which mainly these viruses attached have been shown to contain both $2 \rightarrow 3$ and $2 \rightarrow 6$ linkages by lectin staining [21-24]. Although several factors may be required for crossing host restriction [44, 45], surveillance of transmission between humans or emergence of new pandemic strains has to be increased because they are RNA viruses capable of rapid evolution [1,2].

Another sialic acid derivative, $\mathrm{N}$-glycolylneuraminic acid (Neu5Gc), an additional receptor of some human and animal influenza A viruses [38, 46, 47], could not be detected in $N$-linked glycans of both CAM and AM cells.

The sialic acid with 9-O-acetyl, which serves as a specific primary receptor for influenza $\mathrm{C}$ viruses $[8,9]$ and is recognized by avian (duck) influenza A virus [46], could not be detected in $N$-linked glycans of both CAM and AM cells. However, AM cells have been shown to be susceptible to influenza $C$ viruses [25, 48]. These findings indicate that 9-O-acetyl sialic acid may be carried on $O$ linked glycoproteins or glycolipids, such as gangliosides [8, 49], in AM cells of chicken embryonated eggs.

Unlike sialic acid, little is known about the relationship between sulfated glycans and influenza viruses. There is evidence that some chicken and mammalian influenza A viruses display a high binding affinity for sulfated sialylglycan receptor, and this binding affinity is decreased after treatment of cells with sulfatase [50]. The presence of sulfated Neu5Ac $(\alpha 2 \rightarrow 6) \mathrm{Gal}$ in CAM and AM cells $(1.3 \%$ and $3.8 \%$, respectively, Table 1) may facilitate human influenza virus infection of AM cells. A 6 ' $-\mathrm{HSO}_{3} \mathrm{LacNAc}$ probe without sialic acid was also shown to bind to human influenza type A and B viruses with affinity comparable to that of a $6^{\prime}$-SiaLac probe [51]. The difference in molar percents of sulfated glycans detected in CAM cells (2.5) and AM cells (8.9; Fig. 2) may be a reason why human influenza viruses are more efficiently cultivated in AM cells than in CAM cells.

In summary, by using highly sensitive and efficient analytical techniques, we have identified $N$-glycan structures and have confirmed the presence of both $\alpha 2 \rightarrow 3$ and $\alpha 2 \rightarrow 6$ linkages in $N$-glycans, known to be important for efficient virus entry and infection. CAM and AM cells have different ratios of molar percent of $\operatorname{Neu} 5 \operatorname{Ac}(\alpha 2 \rightarrow 3) \mathrm{Gal}$ to Neu5Ac $(\alpha 2 \rightarrow 6)$ Gal (3.3:1.0 and 1.1:1.0 in CAM and AM cells, respectively) reflecting distinctions in susceptibility of these cells to different influenza virus species and accounting for the binding of viruses cultivated in chicken embryonated eggs to shift to $\mathrm{Neu} 5 \mathrm{Ac}(\alpha 2 \rightarrow 3) \mathrm{Gal}$ specificity. Our data have also shown that CAM and AM cells contain $\mathrm{N}$-glycans with terminal mannose and sulfate residues capable of binding to influenza viruses. However, Neu5Gc and 9-O-Acetyl sialic acid, recognized by some influenza viruses, were not detected in $\mathrm{N}$-glycans of CAM and AM cells.
Acknowledgement This work is supported by a grant-in-aid for Scientific Researsch (B) (20390028) from the Ministry of Education, Culture, Sports, Science and Technology and by a Health and Labour Science Research Grants form Ministry of Health, Labour, and Welfare, Japan. A part of this work was also supported by Tokyo Biochemical Research Foundation, Toukai Foundation for Technology and Daiko foundation, Japan.

Open Access This article is distributed under the terms of the Creative Commons Attribution Noncommercial License which permits any noncommercial use, distribution, and reproduction in any medium, provided the original author(s) and source are credited.

\section{References}

1. Horimoto, T., Kawaoka, Y.: Influenza: lessons from past pandemics, warnings from current incidents. Nat. Rev. Microbiol. 3, 591-600 (2005). doi:10.1038/nrmicro1208

2. Suzuki, Y.: Sialobiology of influenza: molecular mechanism of host range variation of influenza viruses. Biol. Pharm. Bull. 28, 399-408 (2005). doi:10.1248/bpb.28.399

3. Suzuki, Y., Nagao, Y., Kato, H., Matsumoto, M., Nerome, K., Nakajima, K., et al.: Human influenza A virus hemagglutinin distinguishes sialyloligosaccharides in membrane-associated gangliosides as its receptor which mediates the adsorption and fusion processes of virus infection. Specificity for oligosaccharides and sialic acids and the sequence to which sialic acid is attached. J. Biol. Chem 261, 17057-17061 (1986)

4. Chu, V.C., Whittaker, G.R.: Influenza virus entry and infection require host cell N-linked glycoprotein. Proc. Natl. Acad. Sci. U. S.A. 101, 18153-18158 (2004). doi:10.1073/pnas.0405172102

5. Gagneux, P., Cheriyan, M., Hurtado-Ziola, N., van der Linden, E. C., Anderson, D., McClure, H., et al.: Human-specific regulation of alpha 2-6-linked sialic acids. J. Biol. Chem 278, 48245-48250 (2003). doi:10.1074/jbc.M309813200

6. Olofsson, S., Bergstrom, T.: Glycoconjugate glycans as viral receptors. Ann. Med 37, 154-172 (2005). doi:10.1080/ 07853890510007340

7. Rogers, G.N., Paulson, J.C.: Receptor determinants of human and animal influenza virus isolates: differences in receptor specificity of the H3 hemagglutinin based on species of origin. Virology 127, 361-373 (1983). doi:10.1016/0042-6822(83)90150-2

8. Herrler, G., Klenk, H.D.: The surface receptor is a major determinant of the cell tropism of influenza $\mathrm{C}$ virus. Virology 159, 102-108 (1987). doi:10.1016/0042-6822(87)90352-7

9. Vlasak, R., Krystal, M., Nacht, M., Palese, P.: The influenza c virus glycoprotein (HE) exhibits receptor-binding (hemagglutinin) and receptor-destroying (esterase) activities. Virology 160, 419425 (1987). doi:10.1016/0042-6822(87)90013-4

10. Chandrasekaran, A., Srinivasan, A., Raman, R., Viswanathan, K., Raguram, S., Tumpey, T.M., et al.: Glycan topology determines human adaptation of avian $\mathrm{H} 5 \mathrm{~N} 1$ virus hemagglutinin. Nat. Biotechnol 26, 107-113 (2008). doi:10.1038/nbt1375

11. Burnet, F.M., Bull, D.R.: Changes in influenza virus associated with adaptation to passage in chick embryos. Aust. J. Exp. Biol. Med. Sci 21, 55-69 (1943). doi:10.1038/icb.1943.7

12. Martin, M.L., Palmer, E.L., Kendal, A.P.: Lack of characteristic hexagonal surface structure on a newly isolated influenza $\mathrm{C}$ virus. J. Clin. Microbiol 6, 84-86 (1977)

13. Robertson, J.S., Naeve, C.W., Webster, R.G., Bootman, J.S., Newman, R., Schild, G.C.: Alterations in the hemagglutinin associated with adaptation of influenza B virus to growth in eggs. Virology 143, 166174 (1985). doi:10.1016/0042-6822(85)90105-9 
14. Katz, J.M., Wang, M., Webster, R.G.: Direct sequencing of the HA gene of influenza (H3N2) virus in original clinical samples reveals sequence identity with mammalian cell-grown virus. J. Virol 64, 1808-1811 (1990)

15. Nishimura, H., Sugawara, K., Kitame, F., Nakamura, K., Katsushima, N., Moriuchi, H., et al.: A human melanoma cell line highly susceptible to influenza C virus. J. Gen. Virol 70(Pt 7), 1653-1661 (1989). doi:10.1099/0022-1317-70-7-1653

16. Robertson, J.S., Bootman, J.S., Nicolson, C., Major, D., Robertson, E.W., Wood, J.M.: The hemagglutinin of influenza B virus present in clinical material is a single species identical to that of mammalian cell-grown virus. Virology 179, 35-40 (1990). doi:10.1016/0042-6822(90)90270-2

17. Gambaryan, A.S., Robertson, J.S., Matrosovich, M.N.: Effects of egg-adaptation on the receptor-binding properties of human influenza A and B viruses. Virology 258, 232-239 (1999). doi:10.1006/viro.1999.9732

18. Katz, J.M., Naeve, C.W., Webster, R.G.: Host cell-mediated variation in H3N2 influenza viruses. Virology 156, 386-395 (1987). doi:10.1016/0042-6822(87)90418-1

19. Robertson, J.S., Bootman, J.S., Newman, R., Oxford, J.S., Daniels, R.S., Webster, R.G., et al.: Structural changes in the haemagglutinin which accompany egg adaptation of an influenza A(H1N1) virus. Virology 160, 31-37 (1987). doi:10.1016/00426822(87)90040-7

20. Baum, L.G., Paulson, J.C.: Sialyloligosaccharides of the respiratory epithelium in the selection of human influenza virus receptor specificity. Acta Histochem. Suppl 40, 35-38 (1990)

21. Kogure, T., Suzuki, T., Takahashi, T., Miyamoto, D., Hidari, K.I., Guo, C.T., et al.: Human trachea primary epithelial cells express both sialyl(alpha2-3)Gal receptor for human parainfluenza virus type 1 and avian influenza viruses, and sialyl(alpha2-6)Gal receptor for human influenza viruses. Glycoconj. J 23, 101-106 (2006). doi:10.1007/s10719-006-5442-Z

22. Matrosovich, M.N., Matrosovich, T.Y., Gray, T., Roberts, N.A., Klenk, H.D.: Human and avian influenza viruses target different cell types in cultures of human airway epithelium. Proc. Natl. Acad. Sci. U.S.A. 101, 4620-4624 (2004). doi:10.1073/ pnas. 0308001101

23. Nicholls, J.M., Chan, M.C., Chan, W.Y., Wong, H.K., Cheung, C. Y., Kwong, D.L., et al.: Tropism of avian influenza A (H5N1) in the upper and lower respiratory tract. Nat. Med 13, 147-149 (2007). doi:10.1038/nm1529

24. Shinya, K., Ebina, M., Yamada, S., Ono, M., Kasai, N., Kawaoka, Y.: Avian flu: influenza virus receptors in the human airway. Nature 440, 435-436 (2006). doi:10.1038/440435a

25. Ito, T., Suzuki, Y., Takada, A., Kawamoto, A., Otsuki, K., Masuda, H., et al.: Differences in sialic acid-galactose linkages in the chicken egg amnion and allantois influence human influenza virus receptor specificity and variant selection. J. Virol 71, 3357-3362 (1997)

26. Guo, C.T., Takahashi, N., Yagi, H., Kato, K., Takahashi, T., Yi, S. Q., et al.: The quail and chicken intestine have sialyl-galactose sugar chains responsible for the binding of influenza A viruses to human type receptors. Glycobiology 17, 713-724 (2007). doi:10.1093/glycob/cwm038

27. Takahashi, N., Kato, K.: GALAXY (Glycoanalysis by the three axes of MS and chromatography): a web application that assists structural analyses of $\mathrm{N}$-glycans. Trends Glycosci. Glycotechnol 15, 235-251 (2003)

28. Takahashi, N., Nakagawa, H., Fujikawa, K., Kawamura, Y., Tomiya, N.: Three-dimensional elution mapping of pyridylaminated N-linked neutral and sialyl oligosaccharides. Anal. Biochem 226, 139-146 (1995). doi:10.1006/abio.1995.1201

29. Nakagawa, H., Kawamura, Y., Kato, K., Shimada, I., Arata, Y., Takahashi, N.: Identification of neutral and sialyl N-linked oligosaccharide structures from human serum glycoproteins using three kinds of high-performance liquid chromatography. Anal. Biochem 226, 130-138 (1995). doi:10.1006/abio. 1995.1200

30. Yamamoto, S., Hase, S., Fukuda, S., Sano, O., Ikenaka, T.: Structures of the sugar chains of interferon-gamma produced by human myelomonocyte cell line HBL-38. J. Biochem 105, 547555 (1989)

31. Yagi, H., Takahashi, N., Yamaguchi, Y., Kimura, N., Uchimura, K., Kannagi, R., et al.: Development of structural analysis of sulfated $N$-glycans by multidimensional high performance liquid chromatography mapping methods. Glycobiology 15, 1051-1060 (2005). doi:10.1093/glycob/cwi092

32. Reading, P.C., Miller, J.L., Anders, E.M.: Involvement of the mannose receptor in infection of macrophages by influenza virus. J. Virol 74, 5190-5197 (2000). doi:10.1128/JVI.74.11.51905197.2000

33. Auewarakul, P., Suptawiwat, O., Kongchanagul, A., Sangma, C., Suzuki, Y., Ungchusak, K., et al.: An avian influenza H5N1 virus that binds to a human-type receptor. J. Virol 81, 9950-9955 (2007). doi:10.1128/JVI.00468-07

34. Le, Q.M., Kiso, M., Someya, K., Sakai, Y.T., Nguyen, T.H., Nguyen, K.H., et al.: Avian flu isolation of drug-resistant H5N1 virus. Nature 437, 1108 (2005). doi:10.1038/4371108a

35. Nobusawa, E., Aoyama, T., Kato, H., Suzuki, Y., Tateno, Y., Nakajima, K.: Comparison of complete amino acid sequences and receptor-binding properties among 13 serotypes of hemagglutinins of influenza A viruses. Virology 182, 475-485 (1991). doi:10.1016/0042-6822(91)90588-3

36. Rogers, G.N., D'Souza, B.L.: Receptor binding properties of human and animal H1 influenza virus isolates. Virology 173, 317 322 (1989). doi:10.1016/0042-6822(89)90249-3

37. Shinya, K., Hatta, M., Yamada, S., Takada, A., Watanabe, S., Halfmann, P., et al.: Characterization of a human H5N1 influenza A virus isolated in 2003. J. Virol 79, 9926-9932 (2005). doi:10.1128/JVI.79.15.9926-9932.2005

38. Suzuki, Y., Ito, T., Suzuki, T., Holland Jr., R.E., Chambers, T.M., Kiso, M., et al:: Sialic acid species as a determinant of the host range of influenza A viruses. J. Virol 74, 11825-11831 (2000). doi:10.1128/JVI.74.24.11825-11831.2000

39. Tumpey, T.M., Maines, T.R., Van Hoeven, N., Glaser, L., Solorzano, A., Pappas, C., et al.: A two-amino acid change in the hemagglutinin of the 1918 influenza virus abolishes transmission. Science 315, 655-659 (2007). doi:10.1126/science. 1136212

40. Yamada, S., Suzuki, Y., Suzuki, T., Le, M.Q., Nidom, C.A., SakaiTagawa, Y., et al.: Haemagglutinin mutations responsible for the binding of $\mathrm{H} 5 \mathrm{~N} 1$ influenza A viruses to human-type receptors. Nature 444, 378-382 (2006). doi:10.1038/nature05264

41. Stevens, J., Blixt, O., Glaser, L., Taubenberger, J.K., Palese, P., Paulson, J.C., et al:: Glycan microarray analysis of the hemagglutinins from modern and pandemic influenza viruses reveals different receptor specificities. J. Mol. Biol 355, 1143-1155 (2006). doi:10.1016/j.jmb.2005.11.002

42. Stevens, J., Blixt, O., Tumpey, T.M., Taubenberger, J.K., Paulson, J.C., Wilson, I.A.: Structure and receptor specificity of the hemagglutinin from an H5N1 influenza virus. Science 312, 404 410 (2006). doi:10.1126/science. 1124513

43. Belser, J.A., Blixt, O., Chen, L.-M., Pappas, C., Maines, T.R., Van Hoeven, N., et al.: Contemporary North American influenza H7 viruses possess human receptor specificity: implications for virus transmissibility. Proc. Natl. Acad. Sci. U.S.A. 105, 7558-7563 (2008). doi:10.1073/pnas.0801259105

44. Lipatov, A.S., Govorkova, E.A., Webby, R.J., Ozaki, H., Peiris, M., Guan, Y., et al.: Influenza: emergence and control. J. Virol. 78, 8951-8959 (2004). doi:10.1128/JVI.78.17.8951-8959.2004 
45. Neumann, G., Kawaoka, Y.: Host range restriction and pathogenicity in the context of influenza pandemic. Emerg. Infect. Dis 12, 881-886 (2006)

46. Higa, H.H., Rogers, G.N., Paulson, J.C.: Influenza virus hemagglutinins differentiate between receptor determinants bearing $\mathrm{N}$-acetyl-, $\mathrm{N}$-glycollyl-, and $\mathrm{N}, \mathrm{O}$-diacetylneuraminic acids. Virology 144, 279-282 (1985). doi:10.1016/0042-6822(85) 90325-3

47. Ito, T., Suzuki, Y., Suzuki, T., Takada, A., Horimoto, T., Wells, K., et al.: Recognition of $\mathrm{N}$-glycolylneuraminic acid linked to galactose by the alpha2,3 linkage is associated with intestinal replication of influenza A virus in ducks. J. Virol 74, 9300-9305 (2000). doi:10.1128/JVI.74.19.9300-9305.2000

48. Matsuzaki, Y., Takao, S., Shimada, S., Mizuta, K., Sugawara, K., Takashita, E., et al.: Characterization of antigenically and genetically similar influenza $\mathrm{C}$ viruses isolated in Japan during the 1999-2000 season. Epidemiol. Infect 132, 709-720 (2004). doi:10.1017/S0950268804002146

49. Suzuki, Y., Nakao, T., Ito, T., Watanabe, N., Toda, Y., Xu, G., et al.: Structural determination of gangliosides that bind to influenza $\mathrm{A}, \mathrm{B}$, and $\mathrm{C}$ viruses by an improved binding assay: strain-specific receptor epitopes in sialo-sugar chains. Virology 189, 121-131 (1992). doi:10.1016/0042-6822(92)90687-K

50. Gambaryan, A.S., Tuzikov, A.B., Pazynina, G.V., Webster, R.G., Matrosovich, M.N., Bovin, N.V.: H5N1 chicken influenza viruses display a high binding affinity for Neu5Ac $\alpha 2-3 \mathrm{Gal} / 1-4\left(6-\mathrm{HSO}_{3}\right)$ GlcNAc-containing receptors. Virology 326, 310-316 (2004). doi:10.1016/j.virol.2004.06.002

51. Rapoport, E.M., Mochalova, L.V., Gabius, H.J., Romanova, J., Bovin, N.V.: Search for additional influenza virus to cell interactions. Glycoconj. J 23, 115-125 (2006). doi:10.1007/ s10719-006-5444-x 